\title{
OBSERVACCOES SOBRE A NIDIFICACÃO E DESENVOLVIMENTO DE CHRYSEMYS DORBIGNI (DUMERIL \& BIBRON, 1835) (TESTUDINES. EMYDINAE) NA ESTAÇÃO ECOLÓGICA DO TAIM, RIO GRANDE DO SUL
}

\section{ABSTRACT}

Chrysemys dorbigni is a common diurnal turtle in the Taim Ecological Station. Though females may choose nesting sites in the same area they do it isolately, not in groups. Data on female nesting site selection, building of nest and egg laying are given. Under laboratory and field conditions development was followed from the egg stage to the emergence of hatchlings and growth of juveniles. One to 16 eggs are laid per clutch. Nesting activity is coincident with periods of higher temperatures in the field. Abiotic conditions and incidence of predation have been considered to estimate the success of clutches.

\section{INTRODUÇĀO}

A Estação Ecológica do Taim se situa na porção sudeste do Estado do Rio Grande do Sul ( $35^{\circ} 50^{\prime} \mathrm{S}$ e $52^{\circ} 26^{\prime} \mathrm{W}$ ) na faixa litorânea entre a lagoa Mirim e o Oceano Atlântico. Essa área vem sendo estudada desde 1978 sob o ponto de vista de seus biótopos e biocenoses.

Caracteriza-se pelo predomínio de grandes lagoas, como a Mirim e a Mangueira, canais de interligação entre estas e lagoas menores, cortando os campos e também massas d'água sazonais. A leste do grande banhado do Taim, entre este e o Atlântico, estende-se uma larga faixa de dunas. A oeste do banhado, em direção à lagoa Mirim, predominam campos de pastagem baixos, inundáveis nas épocas de maior precipitação. Campos com iguais características estendem-se também ao norte do banhado (campos de Albardão) e ao sul, na área da Fazenda Santa Marta, a oeste da lagoa Mangueira (fig. 1).

\section{MATERIAIS E MÉTODOS}

Foram escolhidos dois sítios com melhores condições de observação. São locais amplos, quase inteiramente planos e situados próximos a corpos de água: 1) área em torno da sede da Estação, num raio estimado de $1 \mathrm{~km}$, cortada por canais; 2) margem oeste da lagoa Mangueira, na Fazenda Santa Marta, numa faixa de $20 \mathrm{~m}$ ao longo de $1 \mathrm{~km}$ (Fig. 1).

Os trabalhos foram iniciados em outubro de 1979, com visitas mensais; no período de nidificação estabeleceu-se uma visita mais intensa, quinzenal, com permanência de 8 a 12 dias cada vez.

A observação da fêmea em postura era realizada através de binóculo (distância aproximada de $200 \mathrm{~m}$ ) ou a olho nu, a uma distância suficiente (7 a $15 \mathrm{~m}$ ) para poder acompanhar seus movimentos sem perturbá-la.

Tão logo as fêmeas abandonavam o local de postura, os ninhos eram recobertos por uma tela de arame de aproximadamente $50 \mathrm{~cm} \times 50 \mathrm{~cm}$, para protegê-los da atividade predatória e propiciar observações posteriores. A tela era ajustada ao solo por grampos de ferro; o mesmo procedimento foi adotado para outros ninhos encontrados intactos.

$1 \& 3$. Departamento de Zoologia, Instituto de Biociências, Universidade Federal do Rio Grande do Sul.

2. Museu de Zoologia, Universidade de São Paulo. 


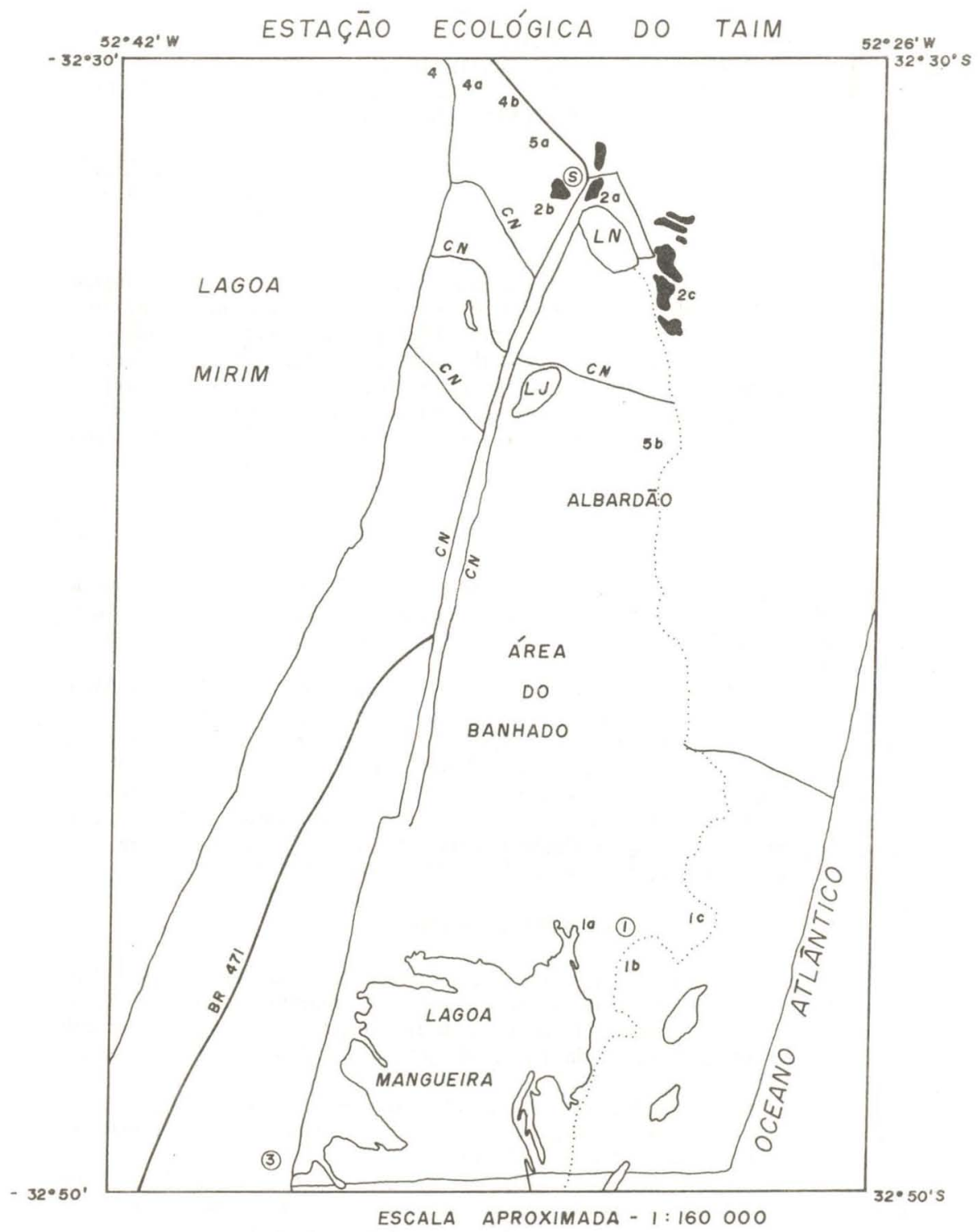

Figura 1 - Estação Ecológica do Taim 1. Área de estudo em torno da Sede (S) da Estação; 2. Área de estudo na Fazenda Santa Marta (SM); LN — Lagoa Nicola; LJ - Lagoa Jacaré; cn - canais principais de interligação; f.m. formações isoladas de mata. 
Ao longo das caminhadas pelo campo, além da busca de fêmeas em postura, também o solo era observado, à procura de pequenas manchas, reconhecidas pela diferença de compactação e, às vezes, cobertas por pequenas quantidades de gramíneas, indício forte da existência de ninhos naqueles pontos. Desta forma muitos ninhos foram identificados sem a presença das fêmeas.

Para acompanhamento, em laboratório, do processo de incubação, eclosão e sobrevivência, recolheram-se os ovos de um ninho cuja postura foi observada. Estes, junto com a terra que os envolvia, foram mantidos em recipientes plásticos de $33 \mathrm{~cm}$ de diâmetro x $13 \mathrm{~cm}$ de altura, conservados na mesma disposição em que foram colocados pela fêmea, umedecidos diariamente e aquecidos por uma lâmpada de $40 \mathrm{~W}$ durante algumas horas. Dos demais ninhos mantidos em observação no campo, alguns serviram para controle de temperatura e acompanhamento dos ovos com relação a peso e tamanho; outros permaneceram intactos.

O controle de temperatura foi realizado através de um perfil de 24 horas, obtendo-se dados do ninho e do solo através de geotermômetros colocados à mesma profundidade $(12 \mathrm{~cm})$ em ambos; a do ar $(1,50 \mathrm{~cm})$ e acima do nível do solo $(22 \mathrm{~cm})$, com termômetros de máximas e mínimas.

Ainda com relação aos ninhos, foram tomadas medidas de diâmetro e profundidade com auxílio de trena. Somente o diâmetro da câmara não foi medido, pois isso ocasionaria a sua destruição.

O controle de peso e tamanho dos ovos foi feito no campo de $20 \mathrm{em}$ 20 dias. As pesagens, realizadas em 50 ovos, no período de 1980/1981 se referem apenas aos ninhos encontrados na área da Sede da Estação, devido à dificuldade de transporte da balança para a Fazenda Santa Marta. Utilizamos balança "Marte", com precisão de décimos de gramas, alcançando $610 \mathrm{~g}$. As medições foram realizadas nos ninhos das duas áreas de estudo, com auxílio de paquímetro. Procedemos da mesma forma com os jovens, após a eclosão, já em laboratório. Durante 20 meses medimos quinzenalmente o comprimento das carapaças e pesamos os filhotes, tanto os que nasceram em laboratório quanto os eclodidos no campo, obtendo dados sobre o seu crescimento. Para a confecção de gráficos de crescimento, apenas filhotes eclodidos no campo $\left(\mathrm{N}_{2}\right.$ e $\left.\mathrm{N}_{3}\right)$ foram registrados por serem mais representativos. Estes foram mantidos inicialmente numa bacia plástica de $42 \mathrm{~cm}$ de diâmetros x $15 \mathrm{~cm}$ de altura, com areia formando declive e pedras no fundo, plantas, tijolos vazados para abrigo, água e aerizador. Após seis meses foram transferidos para um aquário de $35 \times 35 \times 60 \mathrm{~cm}$ e, ao completar um ano, para um tanque "Brasilit" de $75 \times 75 \times 60 \mathrm{~cm}$, com as mesmas características. Em dias frios aquecia-se 0 ambiente com até 3 lâmpadas de $40 \mathrm{~W}$ e/ou $60 \mathrm{~W}$.

\section{RESULTADOS}

\section{Nidificação}

Ocorre em fins de setembro, estendendo-se até fevereiro; a atividade máxima observada ocorreu em dezembro.

A curva de temperaturas médias da região do Taim dos anos de 1979 e 1980, obtidas nos postos metereológicos de Santa Vitória do Palmar e de Rio Grande (Fig. 2) mostra que o período de postura coincide com a época (setembro a março) de temperaturas mais elevadas (em torno de $18^{\circ}$ a $31^{\circ} \mathrm{C}$ ). Nestes dois anos as chuvas foram bem distribuídas, com períodos de menor precipitação em janeiro e maio/junho; pode-se supor que esse fator não influi diretamente no período de nidificação. As posturas, sempre diurnas, ocorrem antes e depois das horas mais quentes do dia: pela manhã, entre 8:00 e 10:00 horas, e ao final da tarde. Nestes horários a temperatura média é de $24^{\circ}$ C (Tab. I).

Cemo se verifica na Tab. I, das 11 posturas observadas, 9 ocorreram em dias de sol, embora tenha-se constatado uma postura sob chuva.

Observa-se com maior freqüência ninhos em áreas de vegetação rasteira (gramíneas) e solo arenoso com grânulos finos e, em menor número, em terre- 


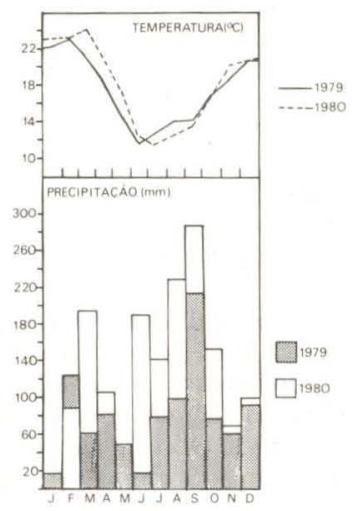

Figura 2 - Médias mensais de temperatura do ar e precipitações, relativas aos anos de 1979 e 1980.

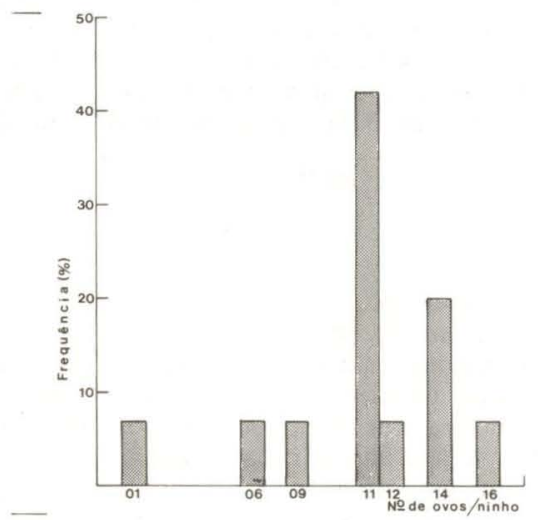

Figura 3 - Relação de $n .^{\circ}$ de ovos/ninho (freqüência relativa) com base em 14 ninhos de Chrysemys dorbigni, examinados nas duas áreas de trabalho na E.E. Taim, no período de dez. 1980/jan. 1981. 
Tabela 1 - Temperatura e hora de 11 posturas de Chrysemys dorbigni, observadas em dez./80 e jan./81, na Estação Ecológica do Taim.

$\begin{array}{ccccl}\begin{array}{c}\text { N. de fêmeas } \\ \text { observadas }\end{array} & \text { Data } & \begin{array}{c}\mathrm{T}\left({ }^{\circ} \mathrm{C}\right) \text { na } \\ \text { hora da } \\ \text { postura }\end{array} & \text { Hora } & \begin{array}{l}\text { Condições } \\ \text { do tempo }\end{array} \\ 01 & 03 / \text { XII } / 80 & 22,0 & 9: 47 & \text { chovendo } \\ 02 & 06 / \text { XII } / 80 & 18,5 & 7: 00 & \text { sol } \\ 06 & 07 / \text { XII } / 80 & 28,0 & 9: 00 & \text { sol } \\ 01 & 08 / \text { XII } / 80 & 31,0 & 9: 10 & \text { sol } \\ 01 & 02 / 1 / 81 & 23,8 & 10: 00 & \text { sem chuva }\end{array}$

nos sem vegetação, onde o solo é mais argiloso. Em locais de vegetação densa nenhum ninho foi encontrado.

A distância entre o local de construção do ninho e a água pode variar de acordo com a declividade do terreno. Em áreas planas ou de pouca declividade são encontrados relativamente afastados da água (40 a $400 \mathrm{~m})$; onde há elevação brusca em relação ao nível da água, como à margem de valas artificiais de irrigação, encontram-se distantes de cerca de $1 \mathrm{~m}$ do nível da água.

\section{Comportamento da fêmea}

As fêmeas saem sempre solitárias da água. Embora, ocasionalmente, construam seus ninhos bastante próóximos uns dos outros, não evidenciam qualquer comportamento social. Houve oportunidade de observar três fêmeas construirem seus ninhos bem próximos, mas estavam em diferentes estágios de nidificação. Após encontrar o local apropriado, a fêmea umedece a terra, liberando uma certa quantidade de urina que, associada à umidade do solo, torna-se bastante plástica e pastosa. Em seguida, escava o terreno com as patas posteriores. Cada uma das patas se movimenta em semi-círculo e são usadas alternadamente. Quando o ninho está suficientemente profundo, inicia-se a postura. Os ovos são dispostos em camadas, cada qual coberta com a terra acumulada em volta do ninho durante a escavação.

$\hat{E}$ interessante notar que a fêmea usa, tanto para intercalar os ovos como para cobrir a superfície do ninho, a mesma quantidade de terra que escavou. Após encobri-lo, aplaina a superfície com movimentos de vai-e-vem laterais do plastrão.

Concluído o trabalho de compactação do terreno, inicia sua lenta caminhada de volta à água. Por vezes parece desorientada, fazendo voltas em torno do ninho ou andando numa direção, para em seguida retroceder. Quando finalmente inicia o percurso de retorno à água, não o faz de uma só vez, mas parando diversas vezes. Esses intervalos podem ser breves (10 minutos) ou mais longos (60 minutos). Quando há sol procura, para essas paradas, um local à sombra, ali ficando com a cabeça erguida; quando chove, para em qualquer local abrigado.

Ao se sentir observada, em qualquer estágio de construção do ninho, interrompe seu trabalho, ficando absolutamente imóvel, mas sem se recolher na carapaça; outras vezes abandona o local sem realizar a desova.

Ninho

É formado por duas porções bem definidas: pescoço e câmara de ovos. O pescoço é a porção inicial, mais afilada; a câmara é preenchida pelos ovos 
dispostos em camadas; seu diâmetro é aproximadamente duas ou três vezes maior que o do pescoço. As medidas do pescoço e da câmara de postura, tomadas de 11 ninhos, encontram-se na Tab. 2.

Tabela 2 - Medidas de 11 ninhos de Chrysemis dorbigni, em dez./80 e jan./81, na Estação Ecológica do Taim.

Elementos Considerados

Profundidade do pescoço

Diâmetro do pescoço

Profundidade total do

ninho (pesc + câmara)

$$
\begin{gathered}
\begin{array}{c}
\text { Extremos } \\
(\mathrm{cm})
\end{array} \\
4,0-12,0 \\
5,0-9,5 \\
9,0-16,5
\end{gathered}
$$

$\begin{array}{cc}\overline{\mathrm{x}}(\mathrm{cm}) & \mathrm{N} .{ }^{\circ} \text { ninhos } \\ 7,9 & 09 \\ 7,3 & 11 \\ 12,8 & 11\end{array}$

Com base em 14 ninhos observados na relação número de ovos/ninhos, a maior freqüência encontrada é de 11 ovos (Fig. 3).

Comparando as medidas de temperatura de um ninho de três dias com as do solo, do nível do solo e da atmosfera, num período de 24 horas, observou-se que o ninho apresentou sempre uma temperatura mais constante frente às demais (Fig. 4).

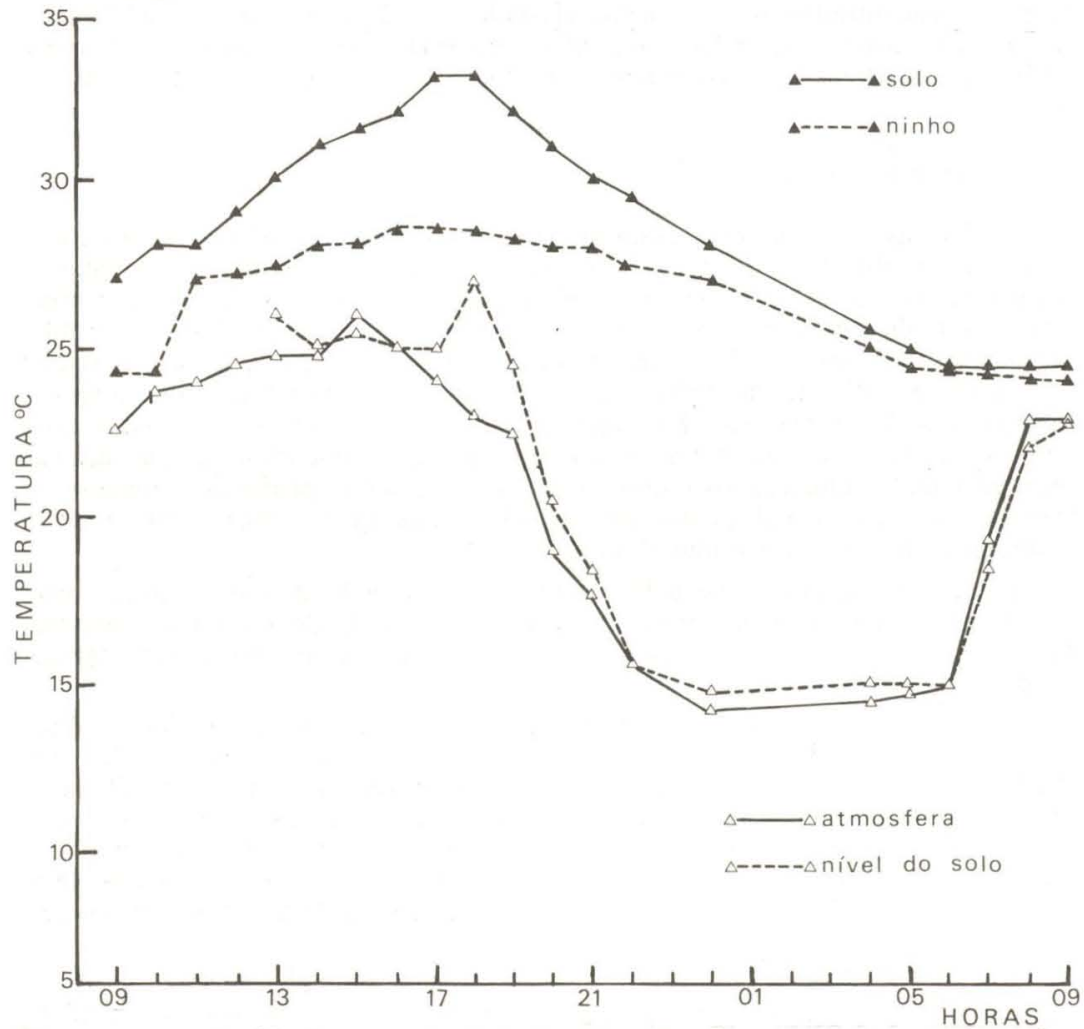

Figura 4 - Perfil de temperatura; comparação das temperaturas do solo, ninho (ambos a $12 \mathrm{~cm}$ de profundidade), a nível do solo $(22 \mathrm{~cm})$ e do ar atmosférico $(150 \mathrm{~cm})$, realizado entre 7 e $8 /$ jan./81, na área da Sede E. T. Taim. As médias e amplitudes destes parâmetros foram, respectivamente: solo: $26,1^{\circ} \mathrm{C}$ e $8,5^{\circ} \mathrm{C}$; ninho: $26,4^{\circ} \mathrm{C}$ e $3,4^{\circ} \mathrm{C}$; atmosfera: $20,9^{\circ} \mathrm{C}$ e $11,9^{\circ} \mathrm{C}$; nível do solo: $20,9^{\circ} \mathrm{C}$ e $14,0^{\circ} \mathrm{C}$. 
Ovos

Logo após a postura, os ovos apresentam a casca flexível e de coloração branco-amarelada. No decorrer da incubação tornam-se mais esbranquiçados, opacos e calcificados. A forma é elipsoidal.

$\mathrm{Na}$ tabela III encontram-se as medidas tomadas em 102 ovos, logo após a postura ou durante a primeira semana de incubação. Destes, apenas 50 foram pesados, provenientes de ninhos da Sede da Estação Ecológica do Taim.

Tabela III - Medidas de ovos de Chrysemys dorbigni, tomadas em dez./80 e jan./81, na Estação Ecológica do Taim.

Parâmetros considerados

Extremos

Comprimento $(\mathrm{cm})$

Largura $(\mathrm{cm})$

Peso $(\mathrm{g})$

$$
\begin{array}{r}
3,55-4,40 \\
2,20-2,70 \\
11,0-19,7
\end{array}
$$

$\overline{\mathrm{x}}$

3,91
$\mathrm{N} .^{\circ}$ de ovos 102

Após 20 dias da tomada das primeiras medidas, efetuou-se novo controle; a média da largura aumentou para $2,52 \mathrm{~cm}$.

Há pouca variação nas medidas dos ovos procedentes dos diferentes ninhos examinados, independentemente do número de ovos por ninho. De acordo com a Fig. 5 não há correlação entre os dois parâmetros considerados.

Os ovos estão dispostos em três ou quatro camadas dentro da câmara de postura. Em geral, as camadas inferior e superior são compostas por ovos inviáveis e/ou estéreis. Foi uma constante, em todos os ninhos observados, os filhotes resultarem das camadas intermediárias. O insucesso dos ovos não se relaciona apenas à esterilidade; há problemas de malformação e mortalidade pré-natal, pois havia, em cada ninho, pelo menos um embrião completo, morto ou malformado.

\section{Observação dos jovens}

O acompanhamento dos jovens resultou do controle de recém-nascidos de três ninhos $\left(\mathrm{N}_{1}, \mathrm{~N}_{2}, \mathrm{~N}_{3}\right)$; os ovos de $\mathrm{N}_{1}$ tiveram toda a sua incubação em laboratório. Os de $\mathrm{N}_{2}$ e $\mathrm{N}_{3}$ desenvolveram-se em seu ambiente natural e os filhotes foram trazidos ao laboratório logo após a eclosão.

O período de incubação variou de 105 a 110 dias; o processo de eclosão entre 3:00 e 3:30 horas, desde o momento do repique até a saída total do ovo. O saco vitelino é conservado por mais 48 horas.

Os jovens aceitaram alimento pela primeira vez após 25 dias de eclosão; a partir daí alimentaram-se nos períodos quentes, diminuindo a aceitação durante o inverno.

As Figs. 6 e 7 mostram o crescimento dos jovens dos ninhos $N_{2}$ e $N_{3}$; o crescimento é lento nos primeiros meses de vida, com uma certa estabilidade durante os períodos de inverno e um acréscimo mais rápido a partir de meados da primavera. Há também uma certa uniformidade nas linhas de crescimento entre filhotes de uma mesma ninhada.

Predação dos ninhos

Embora não tenha sido possível a observação direta dos predadores, a informação dos moradores da região é de que os ninhos são mais comumente atacados por mamíferos, como zorrilhos (Conepatus chinga) e graxains (Cerdocyon thous); aves, como gavião carancho (Polyborus plancus) e gavião chimango (Milvago chimango); por répteis como o lagarto (Tupinambis $\mathrm{sp}$ ) e nelo próprio homem. 


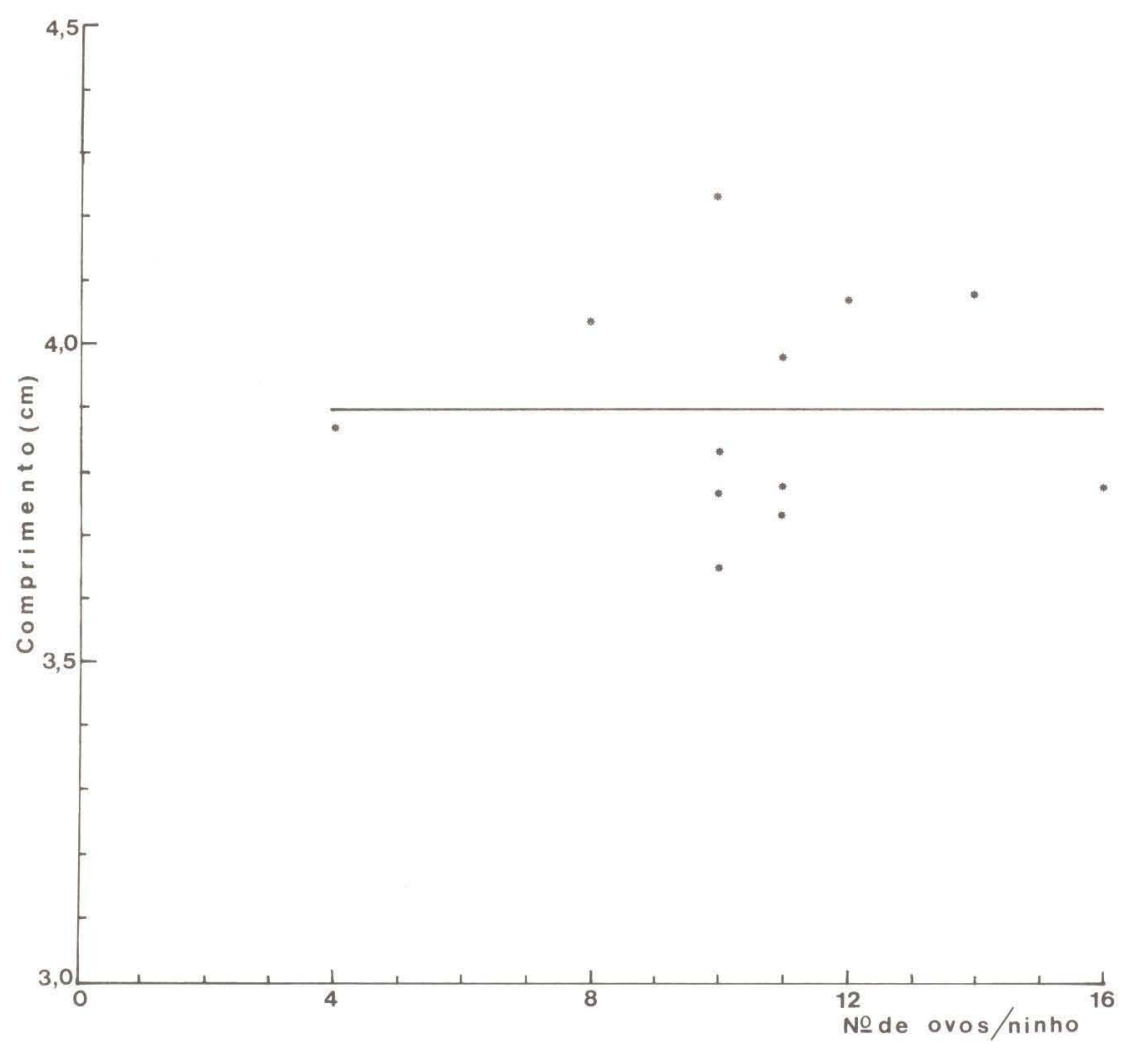

Figura 5 - Tamanho médio do comprimento dos ovos de cada ninho comparado com o número de ovos por ninho, em 12 ninhos de Chrysemy dorbigni, em dez. 1980/jan. 1981, na E. E. Taim. O índice de correlação foi de 0,0046.

Quanto aos invertebrados, constatou-se a presença de formigas em ninhos abertos e em ninhos fechados, onde os ovos estavam alterados. Também foi observada a presença de larvas de moscas num ovo do ninho mantido em laboratório. Ainda se encontrou, num ninho em campo, um adulto de Scapteriscus sp. (paquinha), porém os ovos estavam intactos.

Mesmo nos ninhos protegidos por telas houve predação; alguns destes foram encontrados destruídos ou atacados.

Foi observado que o predador ataca o ninho, com maior freqüência, durante as primeiras 48 horas e o faz de maneira total.

No posto da Fazenda Santa Marta verificou-se, numa faixa de $400 \mathrm{~m}$ x $4,5 \mathrm{~m}$, a presença de 38 ninhos, todos destruídos. Os sinais externos demonstravam que tinham sido destruídos em diferentes ocasiões.

\section{DISCUSSÃO E CONCLUSÕES}

Neste curto período de tempo, os dados permitem um confronto com outras pesquisas.

Chrysemys dorbigni é solitária. Moll \& Legler (1971) afirmam que nenhuma espécie de organização social é citada na literatura para o gênero Pseudemys; as aproximações podem ser consideradas como ocasionais. Já 


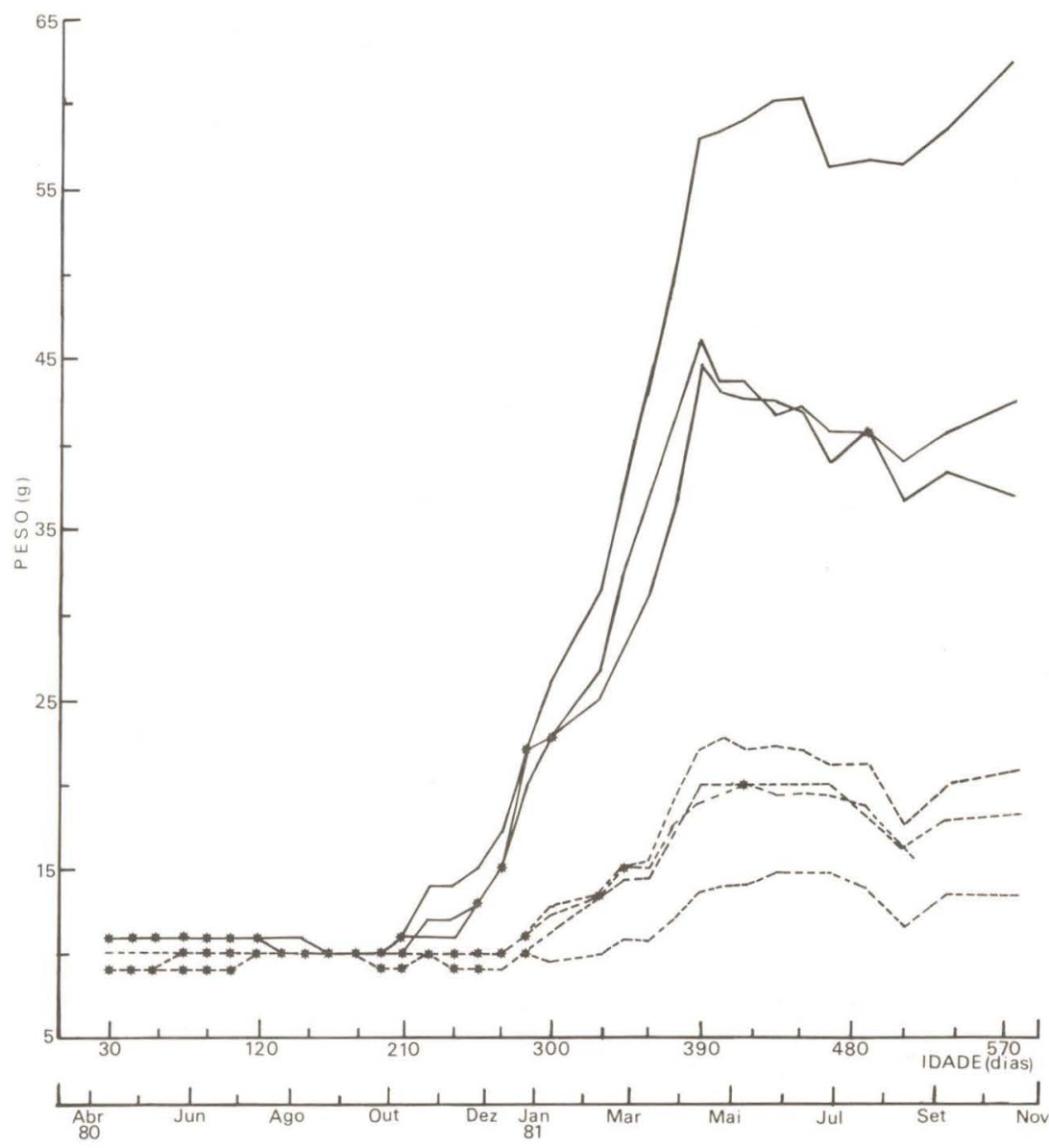

Figura 6 - Peso individual em Chrysemys dorbigni procedentes de 2 ninhos $\left(--\mathrm{N}_{2} ;-\mathrm{N}_{3}\right.$ ) incubados e eclodidos em campo, no período de 1979/1980, na área da Sede E. E. Taim. O desenvolvimento processou-se em laboratório. Os asteriscos representam que, naquelas datas, as medidas de 2 ou mais filhotes apresentaram-se iguais.

Ernst (1971b) comenta que Chrysemys picta não é solitária, sendo sempre encontrada em grandes agregações.

$\mathrm{O}$ período de nidificação estende-se durante os meses mais quentes (de setembro a fevereiro) sendo observada maior atividade durante dezembro e janeiro, o que coincide com as observações de Hirth (1980), sobre as tartarugas em geral, de que há sempre um período no qual essa atividade é mais intensa.

Moll \& Legler (1971) assinalam que para Pseudemys scripta no Panamá, a época de construção do ninho coincide com a estação seca. Como foi observado anteriormente na região do Taim, as chuvas são bem distribuídas durante o ano; logo, a temperatura, mais do que a precipitação, pode representar o fator limite para a época de nidificação de Chrysemys dorbigni. 


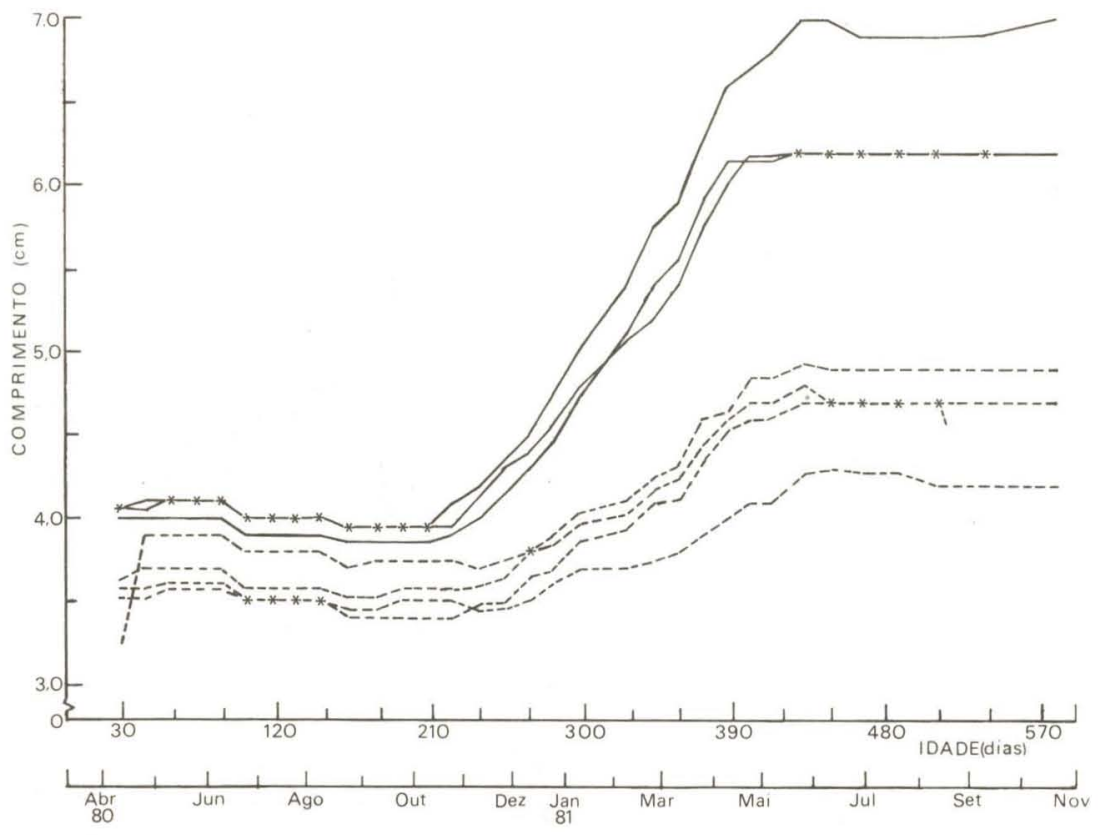

Figura 7 - Crescimento individual em Chrysemys dorbigni em laboratório, procedentes de 2 ninhos $\left(-\cdots \mathrm{N}_{2} ;-\mathrm{N}_{3}\right.$ ) incubados e eclodidos em campo, no período de 1979/1980, área da Sede - E. E. Taim. Os asteriscos representam que, naquelas datas, as medidos de 2 ou mais filhotes apresentaram-se iguais.

Ehrenfeld (1979) afirma que a maioria das tartarugas não marinhas nidificam durante o dia. Os ninhos de Chrysemys dorbigni são construídos nas horas menos quentes do dia, o que indica a possibilidade de que siga esta regra. Tal comportamento, certamente, previne um maior desgaste ou "stress" térmico. Moll \& Legler (1971) observaram o mesmo para Pseudemys scripta, comentando que provavelmente a temperatura é o fator ambiental que limita a construção do ninho durante o dia. Cagle (1937) também assinala para Pseudemys troostii, a postura cedo pela manhã, ou nas horas mais avançadas da tarde.

Com relação à escolha do sítio de postura, observou-se preferência por: a) áreas de vegetação rasteira, que auxilia na proteção do ninho contra a erosão, dessecação, "stress térmico" e predação além de a escavação ser facilitada pela presença de poucas raízes no solo; nestes locais a incidência de ninhos é maior; e, b) terrenos sem vegetação, onde o solo é mais argiloso. Nesses, a umidade natural é aumentada pela excreção da urina da fêmea, permitindo-lhe preparar uma argamassa que protegerá o ninho. Tanto Moll \& Legler (1971) como Ehrenfeld (1979) assinalam que o tipo de solo não é fator determinante para a escolha do local de nidificação; mais importante do que o tipo do solo é a escolha de locais abertos, expostos diretamente ao sol, os ninhos nunca sendo construídos em locais de vegetação densa. Chrysemys dorbigni confirma esse fato. 
A maior ou menor distância entre os ninhos e a água reflete o cuidado da fêmea em procurar lugares seguros contra a inundação, o que traria insucesso para toda a postura. Burger \& Montevecchi (1975) comprovam ser tal comportamento apresentado por tartarugas marinhas e de água doce.

A liberação de certa quantidade de urina no local da construção do ninho é um fato comum entre as tartarugas. Moll \& Legler (1971) sugerem que sua função seria a de marcar o sítio, evitando assim que outras tartarugas viessem a usar o mesmo local. Caso este comportamento seja aplicável a Chrysemys dorbigni, pode-se acrescentar que, além dessa função, parece que ela também utiliza a urina para tornar o solo mais plástico e ajudar a manter sua umidade.

O comportamento da fêmea de Chrysemys dorbigni na escavação do terreno segue o padrão geral das tartarugas; aliás, como assinala Ehrenfeld (1979), esse é um comportamento bem estereotipado para quelônios.

A volta lenta à água, parando diversas vezes no caminho implica, provavelmente, num descanso após o grande esforço despendido na postura. Cagle (1937) e Alho et al. (1979), também observaram esse comportamento; já Pseudemys scripta volta à água sem nenhuma pausa segundo Moll \& Legler (1971).

O comportamento de imobilizar-se e interromper a construção do ninho quando perturbada também é um padrão observado por outros autores; porém, Chrysemys dorbigni não se retrai na carapaça como faz Pseudemys scripta (Moll \& Legler, 1971).

A mudança de aspecto dos ovos, que de flexíveis e amarelados logo após a postura passam a ser mais esbranquiçados e calcificados no decorrer da incubação, foi também observado por outros autores. Moll \& Legler (1971) afirmam que os ovos inviáveis permanecem flexíveis e transparentes, fato também observado em Chrysemys dorbigni.

Durante o controle dos ovos em incubação, evidenciou-se um aumento em seu diâmetro. Este acréscimo, que deve ser uma conseqüuência da absorção de água durante o período de fixação do embrião, foi observado por Cagle (1950) para Pseudemys scripta troostii e Mol \& Legler (1971) para Pseudemys scripta.

Em Chrysemys dorbigni observou-se que não há uma relação entre tamanho dos ovos e número de ovos/ninho, ao contrário do observado por Moll \& Legler (1971) e outros autores citados por eles, de que existe uma tendência geral de posturas pequenas terem ovos maiores.

A medida que as eclosões ocorriam, observou-se que, para cada postura, há uma boa percentagem de ovos estéreis. Hirth (1980) comenta que a maioria desses ovos são postos por último, sugerindo que seriam ovos de "sacrifício", depositados para saciar predadores terrestres. De acordo com o observado em campo, ocorrem ovos estéreis também na camada inferior e os predadores de Chrysemys dorbigni quando atacam, fazem-no de forma total. Portanto, a hipótese de Hirth (1980) não pode ser aplicada aqui. É mais razoável supor que esses ovos inviáveis têm por função a conservação do microclima do ninho, assegurando dessa forma, o sucesso de, pelo menos, um terço da postura. Cagle (1937) e Alho et al. (1979) também sugerem esta hipótese, com base em suas observações.

Segundo o observado por Moll \& Legler (1971), provavelmente a emergência do ninho nunca ocorre imediatamente após a eclosão. Em Chrysemys dorbigni verificou-se ao examinar um ninho no campo que, enquanto alguns jovens estavam abrindo caminho para chegar à superfície, outros estavam apenas eclodindo. Moll \& Legler (1971) comentam, que recém-nascidos de Pseudemys scripta não se dirigem imediatamente para a água, podendo ter uma existência terrestre de até um mês, sendo pouco provável que se alimentem nessa fase; apenas o saco vitelino é utilizado como fonte alimentar. Os jovens de Chrysemys dorbigni demoraram até 25 dias para aceitar o primeiro alimento; no laboratório, pode-se supor que este período corresponda à fase terrestre. 
O crescimento de jovens apresentou variação considerável entre aqueles cujo ninho desenvolveu-se completamente no laboratório e aqueles trazidos logo após a eclosão em campo. Pode-se supor, então, que o retardamento no processo de crescimento deveu-se às condições de laboratório, embora tenha-se procurado uma semelhança com as condições naturais. Ernst (1971a) observa, para Chrysemys picta, que o crescimento é muito variável; indivíduos pequenos geralmente crescem mais rapidamente que os grandes, e salienta que temperatura, chuva e alimento são fatores do meio que influem sobre o crescimento. Como só foram observados jovens em laboratórios, eliminou-se a variação de tais fatores, já que eles foram mantidos a uma mesma temperatura e receberam o mesmo tipo de alimento.

Moll \& Legler (1971) ressaltam que a predação é mais intensa nos dois primeiros dias após a postura, porque os predadores são atraídos pelo odor da urina, que se dilui com o passar do tempo. Os resultados obtidos no presente trabalho, indicam que o predador ataca o ninho de Chrysemys dorbigni, com maior freqüência, durante as primeiras 48 horas, decrescendo sensivelmente sua ação após esse período.

\section{AGRADECIMENTOS}

Agradecemos pelo apoio financeiro recebido do Núcleo Interdepartamental de Ecologia (NIDECO) do Instituto de Biociências da UFRGS, através do convênio MINTER-SEMA/NIDECO-UFRGS, e a permissão para utilização da área da Estação Ecológica do Taim.

\section{REFERENCIAS}

Alho, C. J. R., A. G. Carvalho \& L. F. M. de Pádua, 1979. Ecologia da tartaruga da Amazônia e avaliação de seu manejo na Reserva Biológica de Trombetas. Brasil Florestal 38: 29-47.

Burger, J. \& W. A. Montevecchi, 1975. Nest site selection in the terrapin Malaclemys terrapin. Copeia 1975 (1): 113-119.

Cagle, F. R., 1937. Egg habits of the slider turtle (Pseudemys troostii), the painted turtle (Chrysemys picta) and the musk turtle (Sternostherus odoratus), J. Tenn. Acad. Sci. 12: 87-95.

Cagle, F. R., 1950. The life history of the slider turtle Pseudemys scripta troostii (Holbrook). Ecol. Mon. 20(1): 31-54.

Ehrenfeld, D. W., 1979. Behavior associated with nesting, in M. Harless \& H. H. Marlock (eds.), Turtles: perspectives and research: 417-434. Wiley and Sons, N. Y.

Ernst, C. H., 1971a. Growth of the painted turtle Chrysemys picta in southeastern Pennsylvania. Herpetologica 27: 135-145.

Ernst, C. H., 1971b. Population dynamics and activity cycles of Chrysemys picta in southeastern Pennsylvania. J. Herp. 5(3-4): 151-160.

Hirth, H. F., 1980. Some aspects of the mesting behavior and reproductive biology of sea turtles. Am. Zool. 20: 507-523.

Moll \& J. M. Legler, 1971. The life history of a neotropical slider turtle, Pseudemys scripta (Schoepff) in Panama. Bull. Los Angeles Cty Mus. nat. Sci. 11: 202 p. 